\section{Antiquity of Man in Australia}

For nearly eighty years, one of the most prominent items of anatomical evidence in support of the antiquity of man in Australia has been a fragment of a supposed human molar, found by Krefft in the Wellington Caves of New South Wales.

Early doubts expressed as to the value of its evidence were based on the possibility of its adventitious presence in the caves. These doubts were afterwards dispelled by eye-witnesses, and it is now accepted that the tooth, when found, was imbedded in the characteristic cave breccia, together with remains of Diprotodon and Thylacoleo. According to the estimate of Sir Edgworth David in 1923, the association dates back to a period 7,000-12,000 years ago.

The fossil has been discussed by Krefft (1870-74), Etheridge (1890-1916), David (1923) and Anderson (1933), all of whom have accepted its human origin.

Recently, the human origin of the fragment has been questioned by Dr. T. D. Campbell, and I have considered de novo its possible relation to the lower mammals. To this end, the morphology of the fragment and the type and sequence of the attrition which have produced its crown pattern have been minutely compared with all indigenous Australian mammals, with all introduced and domestic mammals, and with many exotic species as well, which could possibly yield a dental fragment of the size of the fossil. Three chief results have accrued from this examination.

(1) The fossil is derived from a tooth possessing extreme functional brachydonty. At the same time, the occlusal surface exhibits large exposures of dentine in juxtaposition with broad enamel structures. While both features may be separately found in the molars of a few mammals, their concurrence in the same species is generally precluded by the structural ground-plan of the tooth. Consideration of this fundamental peculiarity of the fossil early led me to abandon the view that it was a molar tooth at all.

(2) On transferring attention to premolar teeth, close analogies in structure were soon found to exist between the fossil and the third and fourth premolars of the Macropodinæ, in an advanced stage of wear. In particular, the highly characteristic pattern of the occlusal surface of the fossil is very closely reproduced in the premolars of the black-tailed wallaby (Macropus walabatus L. and G.), and a study of the successive stages of attrition through which such teeth have passed correlates in the clearest way all the main structures of the fossil, with their originating centres in the unworn premolar.

(3) After direct comparison with relevant material, and with the above general conclusions as a guide, I have no doubt that Krefft's find was derived from the posterior half of the upper fourth premolar or seccator, of the right side, of Macropus (Protemnodon) anak, Owen, a giant Pleistocene 'wallaby', remains of which are already known from the caves, and which occur also in profusion in beds of similar and earlier age over a wide area of eastern and southeastern Australia.

A detailed, illustrated account will follow.

South Australian Museum.

H. H. FINLAYSON

\section{Origin of the Golden Hamster Cricetus auratus as a Laboratory Animal}

THE golden (Syrian) hamster Cricetus auratus is now being bred in scientific institutions in Europe and America and has proved useful for various experimental investigations. Workers from different countries have written to me inquiring about the origin of the golden hamster, which is now widely distributed in many laboratories. Some of the correspondents are interested in using Cricetus auratus for genetics, others in the history of this hamster as a laboratory animal.

In 1930 the late Prof. Aharoni, of the Department of Zoology of the Hebrew University, Jerusalem, went on a zoological expedition to Syria (he was particularly interested in the fauna of Antioch). We were engaged on investigations for the Royal Society on Mediterranean kala azar, and the only suitable experimental animal then known was the Chinese hamster, which had to be imported from the Far East and had the additional disadvantage of not breeding in captivity. Stocks could only be replenished by importing, and lengthy experiments in the Middle East were imperilled by epidemics of Pasteurella to which this animal is very susceptible.

Prof. Aharoni undertook to bring specimens of Cricetulus phoeus for our work. In addition to specimens of Cricetulus phoeus (which were also unsatisfactory because they did not breed in captivity), Prof. Aharoni brought back a litter of eight golden hamsters collected near Aleppo which he reared and presented to the Department of Parasitology in July 1930.

Four of the animals escaped, one female was killed by a male and only three animals-one male and two females (all litter mates)-remained. From these three animals Mr. H. Ben Menahem succeeded in raising litters, and it was quickly established that this species breeds readily in captivity. It was first used for investigations on kala azar in November 1930, and was afterwards found valuable for work on tuberculosis and brucellosis. As soon as this was realized, I decided to distribute the animal as widely as possible and avoid the risk of maintaining a valuable species in one laboratory. (The animal is very susceptible to $S$. typhimurium, and wherever there is a danger of contamination with this Salmonella, it is advisable to vaccinate.) I brought specimens to the Collège de France (Prof. Nattan Larrier), to the Medical Research Council and to the Wellcome Bureau of Scientific Research, where Dr. E. Hindle succeeded in breeding them. Shortly before the Second World War I sent animals to India for kala azar research, and the late Prof. I. J. Kligler sent a batch to America. I also sent several batches recently to Egypt. During the War, animals infected with kala azar were sent to the United States at the request of the American Army authorities for experiments on chemotherapy; but these animals were probably not used for breeding.

To the best of my knowledge all the golden hamsters now in use as laboratory animals in Europe and America originate from the above-mentioned three litter mates-one male and two females brought to the Department of Parasitology of the Hebrew University of Jerusalem in July 1930.

It would be interesting to collect more wild specimens from the neighbourhood of Aleppo, and I 